\title{
The longitudinal relationship of changes of adiposity to changes in pulmonary function and risk of asthma in a general adult population
}

Runa V Fenger ${ }^{1 *}$, Arturo Gonzalez-Quintela², Carmen Vidal ${ }^{2}$, Lise-Lotte Husemoen ${ }^{1}$, Tea Skaaby ${ }^{1}$, Betina H Thuesen', Mette Aadahl' ${ }^{1}$, Flemming Madsen ${ }^{3}$ and Allan Linneberg ${ }^{1,4,5}$

\begin{abstract}
Background: Adiposity has been linked to both higher risk of asthma and reduced lung function. The effects of adiposity on asthma may depend on both atopic status and gender, while the relationship is less clear with respect to lung function. This study aimed to explore longitudinal weight changes to changes in forced expiratory volume in first second (FEV1) and forced vital capacity (FVC), as well as to incident cases of asthma and wheezing, according to atopy and gender.

Methods: A general population sample aged 19-72 years was examined with the same methodology five years apart. Longitudinal changes in weight, body mass index, waist circumference, and fat percentage (bio-impedance) were analyzed with respect to changes of FEV1 and FVC (spirometry), and incidence of asthma and wheezing (questionnaire). Gender, atopy (serum specific lgE-positivity to inhalant allergens) and adipose tissue mass prior to adiposity changes were examined as potential effect modifiers.

Results: A total of 2,308 persons participated in both baseline and five-year follow-up examinations. Over the entire span of adiposity changes, adiposity gain was associated with decreasing levels of lung function, whereas adiposity loss was associated with increasing levels of lung function. All associations were dependent on gender (p-interactions $<0.0001)$. For one standard deviation weight gain or weight loss, FEV1 changed with $(+/-)$ $72 \mathrm{ml}(66-78 \mathrm{ml})$ and FVC with (+/-)103 ml $(94-112 \mathrm{ml})$ in males. In females FEV1 changed with (+/-) $27 \mathrm{ml}$ $(22-32 \mathrm{ml})$ and FVC with (+/-) $36 \mathrm{ml}(28-44 \mathrm{ml})$. There were no changes in the FEV1/FVC-ratio. The effect of adiposity changes increased with the level of adipose tissue mass at the start of the study (baseline), thus, indicating an aggregate effect of the total adipose tissue mass. Atopy did not modify these associations. There were no statistically significant associations between changes in adiposity measures and risk of incident asthma or wheeze.

Conclusions: Over a five-year period, increasing adiposity was associated with decreasing lung function, whereas decreasing adiposity was associated with increasing lung function. This effect was significantly greater in males than in females and increased with pre-existing adiposity, but was independent of atopy.
\end{abstract}

Keywords: Adiposity, Asthma, Atopy, FENO, Longitudinal, Lung function, Obesity

\footnotetext{
* Correspondence: Runa.vavia.fenger@regionh.dk

${ }^{1}$ Research Centre for Prevention and Health, The Capital Region of Denmark, Building 84-85, Nordre Ringvej 57, DK-2600 Glostrup, Denmark

Full list of author information is available at the end of the article
} 


\section{Background}

Adiposity has consistently been associated with asthma [1] and has also been associated with impaired lung function, e.g. as assessed by decreased levels of forced expiratory volume in first second (FEV1) and forced vital capacity (FVC) [2-6]. Thus, adiposity may influence the lungs in several ways, e.g. through inflammation leading to asthma-like, obstructive changes, or in terms of a mechanical impact on lung function (restrictive changes).

Adiposity increases the risk of asthma and may cause more severe symptoms along with a reduced response to medications $[1,7,8]$. Some studies have indicated that these effects are stronger in non-atopic individuals than atopic individuals [9-11], although contrary results also have been noted [12]. Further, adiposity has been reported to be more strongly associated with asthma types characterised by non-eosinophilic inflammation rather than by eosinophilic inflammation [13]. However, it has not been investigated whether adiposity also has differential effects on lung function in atopic and non-atopic individuals or in individuals with or without eosinophilic inflammation in the airways. Underlying pathological processes, such as eosinophilic or neutrophilic inflammation [14], could possibly modify the longitudinal relationship of adiposity with lung function.

Mechanically, adiposity may cause an extra load on the thoracic cage [15], increase the intra-abdominal pressure, and impede the movements of the diaphragm [16]. This has in smaller experimental settings been reported to decrease static lung volumes and lead to breathing at smaller tidal volumes [17]. Cross-sectional studies have suggested that these changes are stronger in persons with predominantly abdominal adiposity than in persons with predominantly general adiposity [18]. Yet, prospective population based studies are sparse and have assessed adiposity changes mainly by weight or BMI [2,3,19-22], except from one study that included waist and hip circumferences but not FVC [4]. Therefore, studies quantifying longitudinal changes of lung function with respect to different adiposity phenotypes may add further information about the longitudinal relationship between adiposity and lung function.

This prospective general population study aimed to investigate the association of longitudinal changes in weight, body mass index (BMI), waist circumference (WC), and fat percentage with longitudinal changes in FEV1 and $\mathrm{FVC}$, and with concomitant incidence of asthma and wheezing. Further, we examined whether these associations were modified by gender, atopy, or eosinophilic inflammation of the lower airways as reflected by forced expiratory nitric oxide $\left(\mathrm{F}_{\mathrm{E}} \mathrm{NO}\right)$.

\section{Methods}

\section{Study population}

The current study used already sampled data from the Health2006 study and the Health2006-follow-up study conducted five years apart. The participants in the baseline Health2006 cohort were drawn as a random sample from the background population aged 18-69 years, living in 11 municipalities in the south-western part of suburban Copenhagen. A total of 3471 individuals (44.7\%) entered the study and participated in the health examination, which took place in 2006-08 (Health2006 baseline [23]). In 2011-12, participants in the baseline Health2006 were invited for a 5-year follow-up examination including essentially the same study protocol. A total of 3,405 were eligible for invitation ( 21 had emigrated and 45 died). A total of 2,308 (68.6\%) agreed to participate and were reexamined between November 2011 and November 2012. Fourteen participants did not have valid measures of either FEV1 or FVC at either baseline or follow-up and were excluded from the study, which for the main analyses was based on 2,294 participants. All participants gave written informed consent before taking part in the study, which was approved by the ethics committee of the Capital Region of Denmark, Copenhagen (KA20060011).

\section{Questionnaire data}

Information on socio-demographic variables, leisure time physical activity, smoking habits, chronic illnesses, respiratory symptoms, and medication were obtained from a questionnaire that was mailed to and answered by the participants before their visit to the research centre. Asthma was defined according to the ECRHS criteria [24] as a confirmatory answer to at least one of the following three questions 'Have you been woken by an attack of shortness of breath at any time during the last 12 months?', 'Have you had an attack of asthma within the last 12 months?' and 'Are you currently taking any medication (including inhalers, aerosols or tablets) for asthma?' Wheezing without a cold (in the following referred to as wheezing) was defined as a confirmatory answer to 'Have you had wheezing or whistling in your chest at any time during the last 12 months?' combined with a confirmatory answer to 'If yes, have you had this wheezing or whistling when you did not have a cold?. Smoking was recorded as pack years (one pack year equalling one pack of cigarettes per day for a year) and categorised in five levels: (1) never smokers, (2) $0-\leq 10$, (3) $10-\leq 30$, (4) $30-\leq 50$, or (5) more than 50 pack years but was also used as a continuous measure. Educational level was categorised as: (1) less than 2 years, (2) skilled worker, (3) less than 3 years, (4) 3-4 years, and (5) more than four years. All questions used in the present analyses were identical in the baseline and follow-up studies. 


\section{Physical measurements and assessment of lung function and $\mathrm{F}_{\mathrm{E}} \mathrm{NO}$}

Anthropometric measures were obtained with participants in light clothing and without shoes. Height was measured to the nearest $\mathrm{cm}$, weight to the nearest $0.1 \mathrm{~kg}$, and body mass index (BMI) was calculated as $\mathrm{kg} / \mathrm{m}^{2}$. Waist circumference (WC) was measured to the nearest $\mathrm{cm}$ using a tape measure midway between the lower rib margin and the iliac crest. Fat percentage was measured using a footto-foot Tanita Body Composition Analyzer (TBF-300, TANITA Corporation of America, Inc., Illinois, U.S.A.). Spirometry was performed according to American Thoracic Society and the European Respiratory Society (ATS/ERS) standard [25] using Spiro USB Spirometers (MicroMedical Limited, Rochester, Kent, UK). Spirometers were checked daily with a 3-liter calibrated syringe, and checked every six months with a decompression flow simulator [26]. $\mathrm{F}_{\mathrm{E}} \mathrm{NO}$ measurements were performed only at baseline using a NIOX MINO (Aerocrine AB, Stockholm, Sweden). A dynamic flow restrictor yielded a constant flow rate of $50 \mathrm{~mL} / \mathrm{s}$, in accordance with recommendations of the ATS/ERS guidelines for $\mathrm{F}_{\mathrm{E}} \mathrm{NO}$ measurement [27]. Nitric oxide concentrations between 5 and $300 \mathrm{ppb}$ were measured and measurements below $5 \mathrm{ppb}$ were set to zero by the NIOX MINO. Nitric oxide concentrations above $20 \mathrm{ppb}$ were considered high.

\section{Biomarkers}

Baseline serum samples were analysed for serum specific IgE against the four most clinically important inhalant allergens in Denmark: birch, grass, cat, and the house dust mite Dermatophagoides pteronyssinus, using the ADVIA Centaur Specific IgE assay [28]. Atopy was defined as at least one positive test $(\geq 0.35$ kilo units/L) against specific IgE. Plasma glucose concentrations were analysed by a hexokinase/glucose-6-phosphate dehydrogenase assay (Roche Diagnostic, Germany), and insulin concentrations were measured by fluoroimmunoassay technique (Dako Diagnostics Ltd., UK). The homeostatic model assessment-insulin resistance (HOMA-IR) index was calculated as: fasting plasma glucose $(\mathrm{mmol} / \mathrm{L}) \mathrm{x}$ fasting serum insulin $(\mathrm{mU} / \mathrm{L}) / 22.5$ and applied only to the non-diabetic individuals. High-density lipoprotein (HDL) and triglyceride concentrations were measured by standard enzymatic techniques (Roche Diagnostic, Germany).

\section{Statistics}

We used the R-statistical package, version 3.0.2 (http:// www.r-project.org/) for all analyses. All p-values are twotailed and statistical significance defined as $\mathrm{p}<0.05$. $\mathrm{P}$-values of likelihood ratio tests were used to test for significance of all multivariate analyses. We used linear regression and checked for equal residual variance across the full range of all exposure variables to check the linear model assumptions. We also tested possible non-linear associations by dividing the exposure variables in splines and by testing the quadratic term of the variables in the regression models. For our main analyses, we used absolute or percentage changes (between baseline and fiveyear follow up) of the adiposity measures to changes in FEV1 and FVC. The changes of FEV1 (or FVC) were modelled as five-year FEV1 (or FVC) adjusted for FEV1 (or FVC) at baseline. We also tested the 'reverse' association of baseline lung function measures to changes of adiposity measures. The adiposity measures were standardised by division of each measure by its own standard error to ease interpretation of the regression coefficients and to ease a comparison of the magnitude of effects between the different adiposity measures. In analyses of incidence of asthma and wheezing, logistic regression was used, similar model checks were applied, and the adiposity measures were categorised in four equally sized groups by quartiles of their respective distributions. Possible interactions were tested by adding an interaction term to the regression models, e.g. (adiposity measure"atopy) or (adiposity measure"gender). Finally, all analyses were repeated with s-Trig, s-HDL, and HOMA-IR included in the models to test whether these metabolic markers would attenuate the estimates found for adiposity. Sensitivity analyses included exclusion of the lower and upper 0.0025 , $0.005,0.01$ fractiles of the adiposity measures, as well as separate analyses in non- and never smokers, and in younger or older (age categories were $+/-40,+/-45,+/-50$ years) individuals.

Finally, we made a simulation-model based on randomly generated heights, BMI-levels, and levels of lung volume dependent on height. This model gives an example of how adipose tissue above a certain 'person-dependent ideal' would influence lung function (Additional file 1).

\section{Results}

The baseline characteristics of the study population are given in Table 1. All characteristics are listed separately for participants and non-participants in the follow-up study. Of note is that non-participants as compared to participants had significantly higher levels of adiposity measures and higher levels of FEV1 and FVC. However, the baseline associations of adipose tissue levels with asthma, wheezing, FEV1 or FVC were not significantly different between participants and non-participants, all p-values for interaction between participation and each adiposity measure were between 0.12 and 0.98 . Sensitivity analyses did not change the pattern of results presented.

From baseline to five-year follow-up, lung function was inversely associated with the level of adiposity as reflected by all four adiposity measures. In participants with weight gain, lung function declined; whereas in participants with weight loss, lung function increased to a 
Table 1 Baseline characteristics of the study population according to participation in the five-year follow-up study

\begin{tabular}{|c|c|c|c|c|c|c|}
\hline & & $\begin{array}{l}\text { cipants fol } \\
\qquad N=2294\end{array}$ & & & $\begin{array}{l}\text { rticipants } \\
\mathrm{N}=1163\end{array}$ & \\
\hline & Mean & Sd & $\mathrm{n}$ miss & Mean & Sd & $\mathrm{n}$ miss \\
\hline Age (y) & 50.02 & 12.49 & & 48.02 & 13.98 & \\
\hline FEV1 (liter) & 3.16 & 0.79 & 9 & 3.04 & 0.88 & 5 \\
\hline FVC (liter) & 4.03 & 0.96 & 9 & 3.89 & 1.06 & 5 \\
\hline & $\mathbf{N}$ & $\%$ group & & $\mathrm{N}$ & $\%$ group & \\
\hline Gender & & & & & & \\
\hline Males & 1048 & 45.7 & & 495 & 42.6 & \\
\hline Adiposity measures & & & & & & \\
\hline $18.5>\mathrm{BMI}(\mathrm{kg} / \mathrm{m} 2)$ & 38 & 1.7 & & 27 & 2.3 & \\
\hline $18.5<=\mathrm{BMI}<25(\mathrm{~kg} / \mathrm{m} 2)$ & 1096 & 47.8 & & 491 & 42.2 & \\
\hline $25<=\mathrm{BMI}<30(\mathrm{~kg} / \mathrm{m} 2)$ & 839 & 36.6 & & 408 & 35.1 & \\
\hline $30<=\mathrm{BMI}(\mathrm{kg} / \mathrm{m} 2)$ & 319 & 13.9 & 2 & 237 & 20.4 & \\
\hline WC, normal $\left.\right|^{\S}$ & 1748 & 76.2 & & 359 & 50.7 & \\
\hline WC, high ${ }^{\S}$ & 545 & 23.8 & 2 & 349 & 49.3 & 3 \\
\hline Serum lipids & & & & & & \\
\hline $\mathrm{HDL}$, normal ${ }^{\S}$ & 2036 & 89.1 & 10 & 993 & 86.3 & 13 \\
\hline $\mathrm{HDL}, \operatorname{low}^{\S}$ & 249 & 10.9 & & 158 & 13.7 & \\
\hline Triglyc $<150 \mathrm{mg} / \mathrm{dl}$ & 1901 & 83.2 & & 887 & 77.1 & \\
\hline Triglyc $150-500 \mathrm{mg} / \mathrm{dl}$ & 230 & 10.1 & & 161 & 14.0 & \\
\hline Triglyc $>=500 \mathrm{mg} / \mathrm{dl}$ & 154 & 6.7 & 10 & 103 & 8.9 & 13 \\
\hline Atopy, asthma, wheezing & & & & & & \\
\hline Atopy*, not present & 1741 & 75.9 & & 924 & 79.4 & \\
\hline Atopy*, present & 553 & 24.1 & & 239 & 20.6 & \\
\hline Asthma, not present & 1872 & 82.2 & & 906 & 78.9 & \\
\hline Asthma, present & 405 & 17.8 & 17 & 242 & 21.1 & 15 \\
\hline Wheezing, not present & 1974 & 86.7 & & 915 & 79.9 & \\
\hline Wheezing, present & 303 & 13.3 & 17 & 230 & 20.1 & 18 \\
\hline Lifestyle & & & & & & \\
\hline Smoking, never & 1027 & 48.2 & 18 & 417 & 38.9 & \\
\hline Smoking, $0-\leq 10$ pack years & 492 & 23.1 & & 253 & 23.6 & \\
\hline Smoking, $>10$ pack years & 613 & 28.8 & & 403 & 37.6 & 89 \\
\hline Alcohol, no drinking & 225 & 10.1 & & 159 & 14.3 & \\
\hline Alcohol 1-14 units/week & 1448 & 65.0 & & 714 & 64.4 & \\
\hline Alcohol >14 units/week & 555 & 24.9 & 66 & 236 & 21.3 & 54 \\
\hline Education ${ }^{\S}$, none & 239 & 10.5 & & 215 & 18.8 & \\
\hline Education $^{\S}, 1$ year/practical & 543 & 23.9 & & 272 & 23.8 & \\
\hline Education $^{\S \S}, 2-3$ years & 943 & 41.4 & & 450 & 39.3 & \\
\hline Education $^{\S \S},>=4$ years & 551 & 24.2 & 18 & 208 & 18.2 & 18 \\
\hline
\end{tabular}

FEV1, forced expiratory volumes first second; FVC, forced vital capacity; BMI, body mass index; WC, waist circumference; Diabetes*, either self-reported diabetes or fasting p-glucose $>=7.1 \mathrm{mmol} / \mathrm{L} ; \mathrm{HDL}$, serum level of high-density lipoprotein; Triglyc, serum level of triglyceride; ${ }^{*}$ Atopy defined as serum specific lgE positivity $(>=.35 \mathrm{kU} / \mathrm{l})$ to inhalant allergens; ${ }^{\S}$ above primary school, ${ }^{\$ \S}$ above high school.

similar extend (Figure 1 and Table 2). This pattern was observed in both males and females but the strength of these associations differed significantly between the two genders (Table 2): For all four adiposity measures, the estimated effect of adiposity changes on changes in FEV1 and FVC were approximately three times higher 


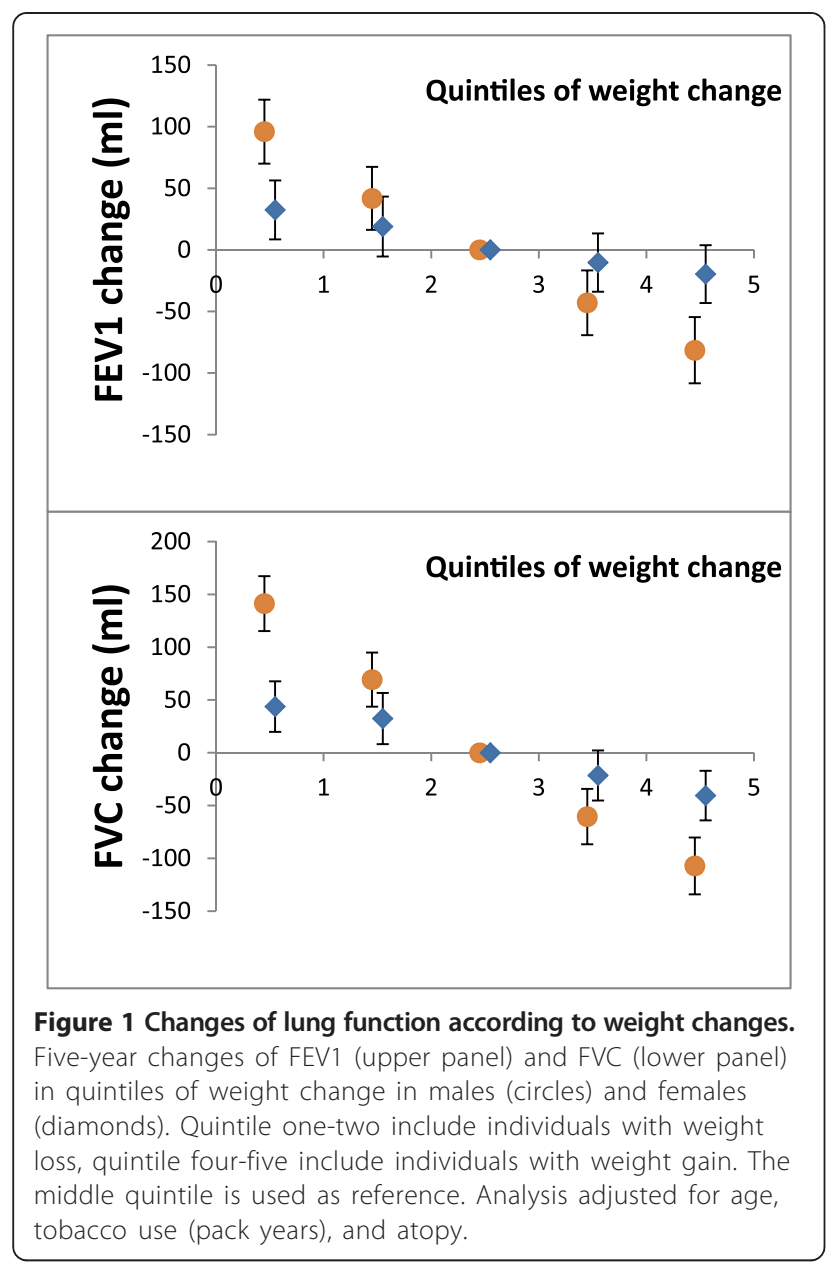

in males than in females in absolute numbers. The percentage changes were the double in males as compared to females. For instance, for every one standard deviation of weight change $(5.4 \mathrm{~kg})$ from baseline to followup, FEV1 either increased or decreased with approximately $72 \mathrm{ml}(66-78 \mathrm{ml})$ in males and $26 \mathrm{ml}(21-31 \mathrm{ml})$ in females, similarly FVC either increased or decreased with $111 \mathrm{ml}(101-121 \mathrm{ml})$ in males and $35 \mathrm{ml}(27-43 \mathrm{ml})$ in females. The metabolic markers, s-triglyceride, s-HDL, or HOMA-IR did not attenuate the effects of adiposity measures on changes in FEV1 and FVC (data not shown). Estimated mean declines for one year of increasing age were approximately $32.8(31.3-34.4) \mathrm{ml} \mathrm{FEV1}$ and 21.4 (19.0-23.9) ml FVC. In never-smokers, the corresponding estimates were 31.0 (28.7-33.3) ml FEV1and 21.0 (17.4-24.6) ml FVC. All age-estimates were essentially similar in males and females but were significantly smaller in younger than in older individuals.

The five-year adiposity changes had a differential impact on lung function changes according to baseline adiposity levels, as assessed as baseline BMI (Figure 2). Five-year adiposity changes were associated with dose-dependent greater declines of FEV1 and FVC in participants who were overweight and obese at baseline as compared to participants who were lean at baseline (Figure 2). Again, this effect was significantly different in males and females but the interaction of baseline-BMI*five-year changes of adiposity was only significant with respect to FVC $(p=0.02)$. Essentially similar results can be obtained by running our simulation example (Additional file 1). There were not any associations between changes of adiposity with changes of the FEV1/FVC-ratio between baseline and follow-up. For one standard deviation change of any adiposity measure, the FEV1/FVC-ratio changed between -0.0023 (fat percentage) to 0.00097 (BMI) in males (p-values 0.14-0.83) and this was not different in females ( $p$ for interactions 0.66-0.99).

To further investigate the temporal relationship of associations between changes in adiposity and lung function, we performed 'reverse' analyses where baseline FEV1 and FVC were used as explanatory variables for subsequent adiposity changes. However, there were no such statistically significant associations. Thus, these results support that changes in adiposity have an influence on lung function, but lung function does not have a similar influence on changes in adiposity.

The inverse association of adiposity with lung function was confirmed in both persons with and without asthma at baseline (Table 3). The gender differences in lung function declines from baseline to follow-up were also independent of asthma status at baseline (Table 3). With respect to atopy and $\mathrm{F}_{\mathrm{E}} \mathrm{NO}$-levels, there were essentially no differences in the associations of adiposity changes to changes of FEV1 and FVC between atopic and non-atopic individuals or between persons with or without elevated $\mathrm{F}_{\mathrm{E}} \mathrm{NO}$-levels (Table 4). Analyses in never- and non-smokers gave similar results (data not shown).

Finally, we investigated whether baseline levels of adiposity measures or changes of adiposity levels from baseline to follow-up were associated with incident asthma and wheezing. The incidence of asthma and wheezing between baseline and follow-up was 7.0\% (158/2265) and $5.9 \%$ (133/2263), respectively. There were no statistically significant associations of any adiposity measure (baseline or changes) with incident asthma but for changes of weight and BMI there was a positive association with wheezing (Table 5). Notably, the novel cases of asthma in our cohort could be categorised as 'late-onset' asthma because all participants were $>=19$ years at baseline. Restricting our analysis further to novel cases of asthma and wheezing in participants e.g. above $>=25$ years or $>=40$ years yielded similar results. There were no differences between atopic and non-atopic individuals or individuals with or without elevated $\mathrm{F}_{\mathrm{E}} \mathrm{NO}$-levels with respect to incident asthma or wheezing (data not shown). 
Table 2 Five-year changes of FEV $(\mathrm{ml})$ and FVC $(\mathrm{ml})$ in males and females per one standard deviation (1 sd) increase of adiposity measure

\begin{tabular}{|c|c|c|c|c|c|c|c|}
\hline & \multicolumn{3}{|c|}{ Males } & \multicolumn{3}{|c|}{ Females } & \multirow[b]{2}{*}{$p-i$} \\
\hline & Est (ml) & Se (ml) & $\mathbf{P}$ & Est (ml) & Se (ml) & $p$ & \\
\hline \multicolumn{8}{|l|}{ FEV1 } \\
\hline Weight (1 sd) & -72.6 & 5.8 & $<.001$ & -27.3 & 4.9 & $<.0001$ & $<.001$ \\
\hline BMI (1 sd) & -78.5 & 6.5 & $<.001$ & -25.5 & 4.6 & $<.0001$ & $<.001$ \\
\hline WC $(1 \mathrm{sd})$ & -66.4 & 6.1 & $<.001$ & -23.4 & 4.8 & $<.0001$ & $<.001$ \\
\hline FatP (1 sd) & -52.0 & 6.2 & $<.001$ & -19.2 & 4.9 & $<.0001$ & $<.001$ \\
\hline \multicolumn{8}{|l|}{ FVC } \\
\hline Weight (1 sd) & -103.2 & 9.0 & $<.001$ & -36.2 & 7.6 & $<.0001$ & $<.001$ \\
\hline BMI (1 sd) & -113.6 & 10.0 & $<.001$ & -32.6 & 7.1 & $<.0001$ & $<.001$ \\
\hline$W C(1 \mathrm{sd})$ & -90.7 & 9.4 & $<.001$ & -28.1 & 7.4 & $<.0001$ & $<.001$ \\
\hline FatP (1 sd) & -54.3 & 9.7 & $<.001$ & -18.0 & 7.6 & 0.01 & 0.002 \\
\hline
\end{tabular}

Linear regression models fitted with interaction between the specific adiposity measure and gender. Adjusted for age, atopy, tobacco use (pack years). Est, beta-estimate; Se, standard error for Est; $p, p$-value; $p$-i, $p$-value for difference (interaction) between males and females; BMI, body mass index; WC, waist circumference; FatP, fat percentage.

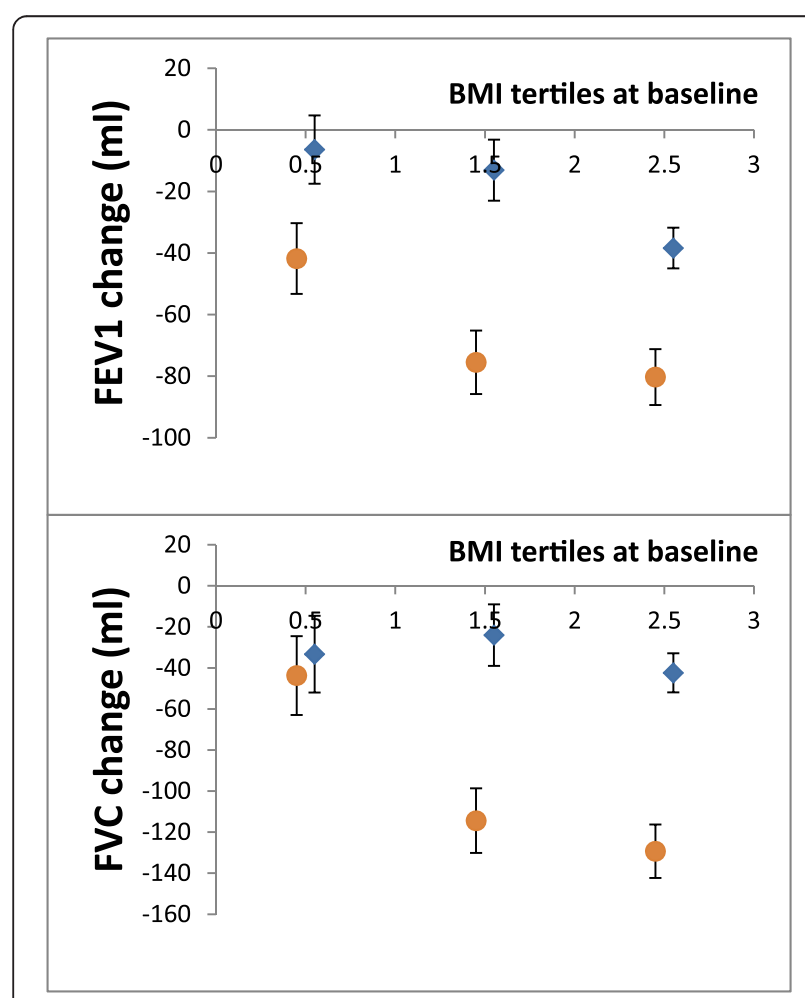

Figure 2 Changes of lung function according to weight changes and baseline adiposity. Five-year changes of FEV1 (upper panel) and FVC (lower panel) per one standard deviation increase of weight between baseline and follow-up according to baseline levels of BMI (X-axis) in males (circles) and females (diamonds), adjusted for age, atopy, tobacco use (pack years), and atopy.

\section{Discussion}

We quantified the longitudinal relationship of several adiposity measures, including waist circumference and fat percentage, with lung function reflected by FEV1 and FVC. Thus, we confirmed changes of FEV1 and FVC per one kilo weight increase as summarised in Additional file 2 and extended that knowledge by reporting longitudinal estimates for abdominal adiposity (waist circumference) and fat percentage. We found that an increase in adiposity over five years was associated with declines in FEV1 and FVC, whereas a decrease in adiposity was associated with increases of FEV1 and FVC. These associations were more pronounced in males than in females but were independent of atopy and $\mathrm{F}_{\mathrm{E}} \mathrm{NO}$-levels. Adiposity changes were not associated with changes in the FEV1/FVC-ratio and were not associated with incident asthma.

Adipose tissue and especially upper body fat have in cross-sectional studies been shown to be associated with decreased static lung volumes as assessed by functional

Table 3 Five-year changes of FEV1 $(\mathrm{ml})$ and FVC $(\mathrm{ml})$ in males and females per one standard deviation increase of BMI from baseline to follow-up, according to asthma status at baseline

\begin{tabular}{lccccccccc}
\hline & \multicolumn{4}{c}{ Males } & & \multicolumn{3}{c}{ Females } \\
\cline { 3 - 5 } & & Est & Se & $\mathbf{p}$ & & Est & Se & $\mathbf{p}$ \\
\hline FEV1 & Asthma & -96.4 & 16.7 & $<.001$ & & -10.7 & 10.8 & 0.32 \\
& Non-asthma & -75.6 & 7.0 & $<.001$ & -29.1 & 5.2 & $<.001$ \\
\multirow{2}{*}{ FVC } & Asthma & -109.7 & 24.4 & $<.001$ & -15.0 & 15.8 & 0.34 \\
& Non-asthma & -115.0 & 11.0 & $<.001$ & & -37.3 & 8.1 & $<.001$ \\
\hline
\end{tabular}

All models fitted with BMI-gender interaction (all interactions significant, $\mathrm{p} \leq .001$ ) and adjusted for age, atopy, and smoking (pack years). BMI, body mass index; Est, beta-estimate; Se, standard error; ml, milliliter; p, p-value for Est. 
Table 4 Five-year changes of FEV ( $\mathrm{ml}$ ) and FVC ( $\mathrm{ml}$ ) in non-atopic and atopic individuals (upper panel), and in individuals with or without elevated FeNO-levels (lower panel), per one standard deviation increase of adiposity measures

\begin{tabular}{|c|c|c|c|c|c|c|c|}
\hline & Est (ml) & Se $(\mathrm{ml})$ & $\mathbf{P}$ & Est (ml) & Se $(\mathrm{ml})$ & $\mathbf{P}$ & $p-i$ \\
\hline & \multicolumn{3}{|c|}{ Non-atopic } & \multicolumn{3}{|c|}{ Atopic } & \\
\hline \multicolumn{8}{|l|}{ FEV1 } \\
\hline Weight (1 sd) & -46.0 & 4.2 & $<.001$ & -46.2 & 8.5 & $<.001$ & ns \\
\hline BMI (1 sd) & -42.3 & 4.2 & $<.001$ & -47.0 & 8.6 & $<.001$ & ns \\
\hline$W C(1 \mathrm{sd})$ & -38.9 & 4.3 & $<.001$ & -43.1 & 8.3 & $<.001$ & ns \\
\hline FatP (1 sd) & -30.6 & 4.3 & $<.001$ & -35.8 & 8.5 & $<.001$ & ns \\
\hline \multicolumn{8}{|l|}{ FVC } \\
\hline Weight (1 sd) & -65.5 & 6.5 & $<.001$ & -59.3 & 13.1 & $<.001$ & ns \\
\hline $\mathrm{BMI}(1 \mathrm{sd})$ & -61.6 & 6.6 & $<.001$ & -54.8 & 13.2 & $<.001$ & ns \\
\hline WC $(1 \mathrm{sd})$ & -53.2 & 6.6 & $<.001$ & -48.6 & 12.8 & $<.001$ & ns \\
\hline \multirow[t]{2}{*}{ Fat (1 sd) } & -32.3 & 6.7 & $<.001$ & -32.1 & 13.1 & $<.02$ & ns \\
\hline & \multicolumn{3}{|c|}{ Normal FeNO $(<=20 \mathrm{ppb})$} & \multicolumn{3}{|c|}{ Elevated FeNO (>20 ppb) } & \\
\hline \multicolumn{8}{|l|}{ FEV1 } \\
\hline Weight (1 sd) & -45.6 & 4.7 & $<.001$ & -48.7 & 7.6 & $<.001$ & ns \\
\hline BMl (1 sd) & -43.4 & 4.7 & $<.001$ & -43.9 & 7.7 & $<.001$ & ns \\
\hline WC $(1 \mathrm{sd})$ & -43.3 & 4.8 & $<.001$ & -31.7 & 7.2 & $<.001$ & ns \\
\hline FatP (1 sd) & -31.8 & 4.8 & $<.001$ & -24.3 & 7.4 & $<.001$ & ns \\
\hline \multicolumn{8}{|l|}{ FVC } \\
\hline Weight (1 sd) & -57.1 & 7.2 & $<.001$ & -85.2 & 12.6 & $<.001$ & 0.04 \\
\hline $\mathrm{BMI}(1 \mathrm{sd})$ & -54.5 & 7.2 & $<.001$ & -78.5 & 12.8 & $<.001$ & ns \\
\hline WC (1 sd) & -48.1 & 7.5 & $<.001$ & -59.4 & 11.9 & $<.001$ & ns \\
\hline FatP (1 sd) & -32.2 & 7.5 & $<.001$ & -28.1 & 12.4 & $<.02$ & ns \\
\hline
\end{tabular}

Linear regression models fitted with interaction between adiposity measure and either atopy or elevated FeNO and adjusted for age, atopy, and smoking (pack years); $\mathrm{p}$-i, $\mathrm{p}$-values for interaction test. Est, beta-estimate; Se, standard error of Est; $\mathrm{p}$, $\mathrm{p}$-value; Atopy defined as serum specific lgE positivity $(>=.35 \mathrm{kU} / \mathrm{l})$ to in halant allergens; FeNO, fractional expiratory nitric oxide;1 sd, one standard deviation; ns, non-significant; BMI, body mass index; WC, waist circumference; FatP, fat percentage.

residual capacity and expiratory reserve volume $[16,17,29]$. As expiratory flow velocity is dependent on the degree of previous lung inflation due to the elastic properties of the lung [30], lower static lung volumes would subsequently impact on expiratory flows. Our results support such mechanical changes in a longitudinal setting. Firstly, the longitudinal adiposity changes were inversely associated with expiratory flow as reflected by FEV1. Secondly, preexisting adiposity (at baseline) enhanced the negative impact of adiposity gain (Figure 2). Thus, the cumulative mass of adipose tissue was associated with reduced lung function as assessed by FEV1 and FVC. Adding that the FEV1/FVC-ratio remained unchanged, there was not a measurable increasing obstructive pattern with increasing adiposity. In comparison, inflammatory mechanisms would be expected to induce asthma-like, obstructive alterations in lung function [31].

The gender differences in the adiposity-lung function associations in this study were substantial, and may emphasise the mechanical aspects as males have more abdominal fat for the same degree of adiposity than females [32]. Similar conclusions have been put forward by authors in other studies $[4,33,34]$ but supplementary explanations may exist. At least in asthma patients, recent cluster analyses have shown that a subgroup of non-adipose males have a high yearly loss of FEV1 that is not explained by presence or absence of atopy, the duration of disease etc. [35,36]. This could indicate that another pathological mechanism towards declines of lung volumes occurs in those males, and this could also apply to males without asthma. Differences in sex hormonal levels, which are emphasised by decreasing gender differences in lung volume decline in elderly [3] is a possible explanation for an apparently different airway pathology in males and females. Other possibilities are different thresholds for the detrimental effects of pulmonary irritants, or differences in airway calibre between males and females [37], although none have been fully documented so far.

Atopy or $\mathrm{F}_{\mathrm{E}} \mathrm{NO}$-levels did not modify the effects of adiposity on lung function. Thus, an underlying atopic as compared to non-atopic condition or an underlying 
Table 5 The association of changes of adiposity measures (quartiles) between baseline and five-year follow-up with risk of novel (incident) asthma and wheezing

\begin{tabular}{|c|c|c|c|c|c|c|c|c|c|c|c|c|}
\hline & & \multirow[b]{2}{*}{$\mathbf{N}$} & \multicolumn{5}{|c|}{ Incident asthma } & \multicolumn{5}{|c|}{ Incident wheezing } \\
\hline & & & $n$ & $n / N$ & OR & $\mathrm{Cl} 1$ & $\mathrm{Cl} 2$ & $n$ & $n / N$ & OR & $\mathrm{Cl} 1$ & $\mathrm{Cl} 2$ \\
\hline Weight & $\mathrm{Kg}$ & & & & & & & & & & & \\
\hline$q 1$ & $<-1.93$ & 570 & 32 & 5.7 & ref & - & - & 26 & 4.7 & ref & - & - \\
\hline q2 & $1.93-<0.7$ & 573 & 47 & 8.3 & 1.47 & 0.91 & 2.42 & 27 & 4.7 & 0.89 & 0.48 & 1.63 \\
\hline q3 & $0.7-<3.2$ & 570 & 32 & 5.7 & 0.95 & 0.56 & 1.62 & 34 & 6.0 & 1.25 & 0.72 & 2.20 \\
\hline q4 & $>3.2$ & 576 & 46 & 8.1 & 1.17 & 0.71 & 1.95 & 46 & 8.1 & 1.57 & 0.93 & 2.70 \\
\hline BMI & $\mathrm{Kg} / \mathrm{m}^{2}$ & & & & & & & & & & & \\
\hline$q 1$ & $<-0.57$ & 572 & 36 & 6.4 & ref & - & - & 25 & 4.5 & ref & - & - \\
\hline q2 & $-0.57-<0.31$ & 572 & 43 & 7.6 & 1.17 & 0.72 & 1.90 & 27 & 4.8 & 1.02 & 0.56 & 1.86 \\
\hline q3 & $0.31-<1.216$ & 572 & 36 & 6.4 & 1.00 & 0.61 & 1.65 & 35 & 6.2 & 1.35 & 0.77 & 2.41 \\
\hline q4 & $>1.22$ & 573 & 42 & 7.4 & 0.88 & 0.53 & 1.43 & 46 & 7.1 & 1.69 & 0.99 & 2.94 \\
\hline WC & $\mathrm{Cm}$ & & & & & & & & & & & \\
\hline q1 & $<-1.5$ & 564 & 30 & 5.4 & Ref & - & - & 27 & 4.9 & ref & - & - \\
\hline q2 & $-1.5-<2$ & 576 & 39 & 6.9 & 1.15 & 0.68 & 1.96 & 25 & 4.4 & 0.85 & 0.46 & 1.57 \\
\hline q3 & $2-<5$ & 525 & 45 & 8.7 & 1.62 & 0.98 & 2.71 & 43 & 8.3 & 1.67 & 0.98 & 2.91 \\
\hline q4 & $>5$ & 626 & 43 & 6.9 & 1.14 & 0.69 & 1.91 & 38 & 6.2 & 1.27 & 0.74 & 2.22 \\
\hline FatP & Percentage points & & & & & & & & & & & \\
\hline$q 1$ & $<-1.40$ & 569 & 32 & 5.7 & ref & - & - & 31 & 5.0 & ref & - & - \\
\hline q2 & $-1.40-<0.50$ & 570 & 47 & 8.3 & 1.45 & 0.89 & 2.38 & 34 & 6.0 & 1.13 & 0.66 & 1.96 \\
\hline q3 & $0.50-<2.402$ & 569 & 42 & 7.5 & 1.24 & 0.75 & 2.06 & 25 & 4.5 & 0.77 & 0.42 & 1.38 \\
\hline q4 & $>2.40$ & 570 & 33 & 5.8 & 0.78 & 0.45 & 1.35 & 40 & 7.1 & 1.20 & 0.71 & 2.05 \\
\hline
\end{tabular}

Number of participants in each group ( $\mathrm{N}$ ), number of novel cases ( $\mathrm{n}$ ) and age, gender, and tobacco (pack years) adjusted odds ratios (OR) with $95 \%$ confidence intervals (Cl1-Cl2)); q1-q4, quartiles 1-4; BMI, body mass index; WC, waist circumference; FatP, Fat percentage.

eosinophilic as compared to non-eosinophilic airway inflammation did not appear to enhance the inverse association of adiposity with lung function in our general population. It is possible that a characterisation of participants by e.g. eosinophils in sputum or blood would have yielded other results, as elevated FENO-levels only are indicative of eosinophil airway inflammation [38]. For instance, cluster analyses have indicated that some groups of asthma patients are characterised by eosinophil airway inflammation and low lung function [39]. Further, faster declines of lung volumes in non-atopic as compared to atopic asthma patients have also been reported $[36,40,41]$. However, our study was conducted in a general population and not in specific groups of patients. Thus, absence of effect modification by atopy or $\mathrm{F}_{\mathrm{E}} \mathrm{NO}$-levels in our study appears to emphasise restrictive changes of lung function with increasing adiposity. However, our study was not powered to investigate effect modifications. Therefore, more studies are needed to confirm or refute the presence of effect modification by atopy or elevated $\mathrm{F}_{\mathrm{E}} \mathrm{NO}$-levels.

We did not find an association between increasing adiposity and asthma incidence but for increasing weight and BMI there was a positive association with incident wheezing. This is in contrast with findings of most longitudinal studies, which have reported a positive association between increasing BMI and incidence of asthma [1]. However, the power to detect such differences in the present study was relatively low as indicated by relatively wide 95\% confidence intervals. Possibly, testing the association of adiposity with bronchial hyperreactivity (BHR) would have yielded other results; in a previous study we found a positive association of adiposity with BHR [42], but such information was not available in the current study.

The strengths of the study include the prospective design, validated and similar methods for measurements of FEV1 and FVC at baseline and follow-up, assessment of atopy by serum specific IgE and airway eosinophil inflammation by $\mathrm{F}_{\mathrm{E}} \mathrm{NO}$. The limitations include the lack of tests for variability of lung function to define asthma, lack of measures of lung volumes, and that the analyses are based on the assumption that increases or decreases of weight and BMI were due to adipose tissue and not muscle mass. Selection bias may have decreased the generalisability of the study and loss to follow-up influenced the reported associations. However, we found similar baseline associations of adipose tissue measures with all 
outcomes in participants and non-participants in the follow-up indicating that our results may apply to a general population.

\section{Conclusion}

In conclusion, changes of adiposity had a high, gender specific impact on FEV1 and FVC but not on the FEV1/ FVC-ratio. Increasing adiposity was associated with lung function decline, whereas loss of adiposity was associated with increasing lung function. These associations were independent of atopy, $\mathrm{F}_{\mathrm{E}} \mathrm{NO}$-levels, and metabolic markers, but were modified by the level of adipose tissue prior to the adiposity changes indicating the importance of aggregate adipose tissue mass. The adiposity changes leading to declines of FEV1 and FVC were not concomitantly associated with incidence of asthma or wheezing, however, a low number of novel cases of asthma and wheezing may have limited the power to detect associations with these outcomes.

\section{Additional files}

Additional file 1: Simulation model of lung function depending on BMI.

Additional file 2: Overview of longitudinal studies of the association between increasing adiposity and decreasing lung function conducted in general adult populations.

\section{Competing interests}

The authors declare that they have no competing interests.

\section{Authors' contributions}

RVF and TS carried out the analyses and drafted the paper. AGQ, CV, LLH, and $\mathrm{AL}$ designed the study and helped to draft the manuscript. FM collected the spirometry data and participated in the design of the study. BHT and MA helped to draft the manuscript. All authors read and approved the final manuscript.

\section{Acknowledgements}

We are very grateful for the funding that we have received from: Aase and Einar Danielsens Foundation and The Danish Scientific Research Council and the Danish Lung Association.

\section{Author details}

${ }^{1}$ Research Centre for Prevention and Health, The Capital Region of Denmark, Building 84-85, Nordre Ringvej 57, DK-2600 Glostrup, Denmark. ²Department of Medicine, Complejo Hospitalario Universitario, Santiago de Compostella, Spain. ${ }^{3}$ The Danish Lung function Laboratory, Helsingør, Denmark. ${ }^{4}$ Department of Clinical Experimental Research, Glostrup University Hospital, Glostrup, Denmark. ${ }^{5}$ Department of Clinical Medicine, Faculty of Health and Medical Sciences, University of Copenhagen, Copenhagen, Denmark.

Received: 17 June 2014 Accepted: 12 November 2014

Published: 22 December 2014

\section{References}

1. Beuther DA, Sutherland ER: Overweight, obesity, and incident asthma: a meta-analysis of prospective epidemiologic studies. Am J Respir Crit Care Med 2007, 175:661-666.

2. Chinn S, Jarvis D, Melotti R, Luczynska C, Ackermann-Liebrich U, Anto JM, Cerveri I, de MR, Gislason T, Heinrich J, Janson C, Kunzli N, Leynaert B, Neukirch F, Schouten J, Sunyer J, Svanes C, Vermeire P, Wjst M, Burney P:
Smoking cessation, lung function, and weight gain: a follow-up study. Lancet 2005, 365:1629-1635.

3. Rossi A, Fantin F, Di FV, Guariento S, Giuliano K, Fontana G, Micciolo R, Solerte SB, Bosello O, Zamboni M: Body composition and pulmonary function in the elderly: a 7-year longitudinal study. Int J Obes (Lond) 2008, 32:1423-1430.

4. Carey IM, Cook DG, Strachan DP: The effects of adiposity and weight change on forced expiratory volume decline in a longitudinal study of adults. Int J Obes Relat Metab Disord 1999, 23:979-985.

5. Chinn DJ, Cotes JE, Reed JW: Longitudinal effects of change in body mass on measurements of ventilatory capacity. Thorax 1996, 51:699-704.

6. Wannamethee SG, Shaper AG, Whincup PH: Body fat distribution, body composition, and respiratory function in elderly men. Am J Clin Nutr 2005, 82:996-1003.

7. Sutherland ER: Linking obesity and asthma. Ann N Y Acad Sci 2014, 1311:31-41.

8. Mosen DM, Schatz M, Magid DJ, Camargo CA Jr: The relationship between obesity and asthma severity and control in adults. J Allergy Clin Immunol 2008, 122:507-511.

9. Kronander UN, Falkenberg M, Zetterstrom O: Prevalence and incidence of asthma related to waist circumference and BMI in a Swedish community sample. Respir Med 2004, 98:1108-1116.

10. Appleton SL, Adams RJ, Wilson DH, Taylor AW, Ruffin RE: Central obesity is associated with nonatopic but not atopic asthma in a representative population sample. J Allergy Clin Immunol 2006, 118:1284-1291.

11. Granell R, Henderson AJ, Evans DM, Smith GD, Ness AR, Lewis S, Palmer TM, Sterne JA: Effects of BMI, fat mass, and lean mass on asthma in childhood: a Mendelian randomization study. PLoS Med 2014, 11:e1001669.

12. Ronmark E, Andersson C, Nystrom L, Forsberg B, Jarvholm B, Lundback B: Obesity increases the risk of incident asthma among adults. Eur Respir J 2005, 25:282-288.

13. Haldar P, Pavord ID, Shaw DE, Berry MA, Thomas M, Brightling CE, Wardlaw AJ, Green RH: Cluster analysis and clinical asthma phenotypes. Am J Respir Crit Care Med 2008, 178:218-224.

14. Scott HA, Gibson PG, Garg ML, Wood LG: Airway inflammation is augmented by obesity and fatty acids in asthma. Eur Respir J 2011, 38(3):594-602.

15. Salome CM, King GG, Berend N: Physiology of obesity and effects on lung function. J Appl Physiol (1985) 2010, 108:206-211.

16. Steier J, Lunt A, Hart N, Polkey MI, Moxham J: Observational study of the effect of obesity on lung volumes. Thorax 2014, 69(8):752-759.

17. Jones RL, Nzekwu MM: The effects of body mass index on lung volumes. Chest 2006, 130:827-833

18. Wehrmeister FC, Menezes AM, Muniz LC, Martinez-Mesa J, Domingues MR, Horta BL: Waist circumference and pulmonary function: a systematic review and meta-analysis. Syst Rev 2012, 1:55

19. Thyagarajan B, Jacobs DR Jr, Apostol GG, Smith L, Jensen RL, Crapo RO, Barr RG, Lewis CE, Williams OD: Longitudinal association of body mass index with lung function: the CARDIA study. Respir Res 2008, 9:31.

20. Bottai M, Pistelli F, Di PF, Carrozzi L, Baldacci S, Matteelli G, Scognamiglio A, Viegi G: Longitudinal changes of body mass index, spirometry and diffusion in a general population. Eur Respir J 2002, 20:665-673.

21. Pistelli F, Bottai M, Carrozzi L, Pede FD, Baldacci S, Maio S, Brusasco V, Pellegrino R, Viegi $G$ : Changes in obesity status and lung function decline in a general population sample. Respir Med 2008, 102:674-680.

22. Chen $Y$, Horne SL, Dosman JA: Body weight and weight gain related to pulmonary function decline in adults: a six year follow up study. Thorax 1993, 48:375-380.

23. Thuesen BH, Cerqueira C, Aadahl M, Ebstrup JF, Toft U, Thyssen JP, Fenger RV, Hersoug LG, Elberling J, Pedersen $O$, Hansen T, Johansen JD, Jorgensen T, Linneberg A: Cohort profile: the health2006 cohort, research centre for prevention and health. Int J Epidemio/ 2014, 43(2):568-575

24. Berg ND, Husemoen LL, Thuesen BH, Hersoug LG, Elberling J, Thyssen JP, Carlsen BC, Johansen JD, Menne T, Bonnelykke K, Stender S, Meldgaard M, Szecsi PB, Linneberg A: Interaction between filaggrin null mutations and tobacco smoking in relation to asthma. J Allergy Clin Immunol 2012, 129:374-380. 380.

25. Miller MR, Hankinson J, Brusasco V, Burgos F, Casaburi R, Coates A, Crapo $R$, Enright $P$, van der Grinten $C P$, Gustafsson $P$, Jensen $R$, Johnson DC, Macintyre N, McKay R, Navajas D, Pedersen OF, Pellegrino R, Viegi G, Wanger J: Standardisation of spirometry. Eur Respir J 2005, 26:319-338 
26. Pedersen OF, Naeraa $N$, Lyager $S$, Hilberg C, Larsen L: A device for evaluation of flow recording equipment. Bull Eur Physiopathol Respir 1983, 19:515-520.

27. ATS/ERS recommendations for standardized procedures for the online and offline measurement of exhaled lower respiratory nitric oxide and nasal nitric oxide, 2005. Am J Respir Crit Care Med 2005, 171:912-930.

28. Petersen AB, Gudmann P, Milvang-Gronager $P$, Morkeberg R, Bogestrand $S$, Linneberg A, Johansen N: Performance evaluation of a specific IgE assay developed for the ADVIA centaur immunoassay system. Clin Biochem 2004, 37:882-892.

29. Sutherland TJ, Goulding A, Grant AM, Cowan JO, Williamson A, Williams SM, Skinner MA, Taylor DR: The effect of adiposity measured by dual-energy X-ray absorptiometry on lung function. Eur Respir J 2008, 32:85-91.

30. Hayes D Jr, Kraman SS: The physiologic basis of spirometry. Respir Care 2009, 54:1717-1726.

31. Shore SA: Obesity, airway hyperresponsiveness, and inflammation. J Appl Physiol 2010, 108:735-743.

32. Bjorntorp P: Adipose tissue distribution and function. Int J Obes 1991. 15(Suppl 2):67-81.

33. Chen Y, Rennie D, Cormier YF, Dosman J: Waist circumference is associated with pulmonary function in normal-weight, overweight, and obese subjects. Am J Clin Nutr 2007, 85:35-39.

34. Leone N, Courbon D, Thomas F, Bean K, Jego B, Leynaert B, Guize L, Zureik M: Lung function impairment and metabolic syndrome: the critical role of abdominal obesity. Am J Respir Crit Care Med 2009, 179:509-516.

35. Moore WC, Meyers DA, Wenzel SE, Teague WG, Li H, Li X, D'Agostino R Jr, Castro M, Curran-Everett D, Fitzpatrick AM, Gaston B, Jarjour NN, Sorkness R, Calhoun WJ, Chung KF, Comhair SA, Dweik RA, Israel E, Peters SP, Busse WW, Erzurum SC, Bleecker ER: Identification of asthma phenotypes using cluster analysis in the severe asthma research program. Am J Respir Crit Care Med 2010, 181:315-323.

36. Amelink M, de Nijs SB, Berger M, Weersink EJ, Ten BA, Sterk PJ, Bel EH: Non-atopic males with adult onset asthma are at risk of persistent airflow limitation. Clin Exp Allergy 2012, 42:769-774.

37. Chen Y, Rennie DC, Pahwa P, Dosman JA: Pulmonary function in adults with recent and former asthma and the role of sex and atopy. BMC Pulm Med 2012, 12:32

38. Dweik RA, Boggs PB, Erzurum SC, Irvin CG, Leigh MW, Lundberg JO, Olin AC, Plummer AL, Taylor DR: An official ATS clinical practice guideline: interpretation of exhaled nitric oxide levels (FENO) for clinical applications. Am J Respir Crit Care Med 2011, 184:602-615.

39. Wu W, Bleecker E, Moore W, Busse WW, Castro M, Chung KF, Calhoun WJ, Erzurum S, Gaston B, Israel E, Curran-Everett D, Wenzel SE: Unsupervised phenotyping of severe asthma research program participants using expanded lung data. J Allergy Clin Immunol 2014, 133:1280-1288.

40. Marcon A, Corsico A, Cazzoletti L, Bugiani M, Accordini S, Almar E, Cerveri I, Gislason D, Gulsvik A, Janson C, Jarvis D, Martinez-Moratalla J, Pin I, de MR: Body mass index, weight gain, and other determinants of lung function decline in adult asthma. J Allergy Clin Immunol 2009, 123:1069-1074. 1074

41. Ulrik CS, Backer V, Dirksen A: A 10 year follow up of 180 adults with bronchial asthma: factors important for the decline in lung function. Thorax 1992, 47:14-18.

42. Fenger RV, Linneberg A, Vidal C, Vizcaino L, Husemoen LL, Aadahl M, Gonzalez-Quintela A: Determinants of serum tryptase in a general population: the relationship of serum tryptase to obesity and asthma. Int Arch Allergy Immunol 2012, 157:151-158.

doi:10.1186/1471-2466-14-208

Cite this article as: Fenger et al:: The longitudinal relationship of changes of adiposity to changes in pulmonary function and risk of asthma in a general adult population. BMC Pulmonary Medicine 2014 14:208

\section{Submit your next manuscript to BioMed Central and take full advantage of:}

- Convenient online submission

- Thorough peer review

- No space constraints or color figure charges

- Immediate publication on acceptance

- Inclusion in PubMed, CAS, Scopus and Google Scholar

- Research which is freely available for redistribution 